\title{
A candidate multimodal functional genetic network for thermal adaptation
}

Vertebrate ectotherms such as reptiles provide ideal organisms for the study of adaptation to environmental thermal change. Comparative genomic and exomic studies can recover markers that diverge between warm and cold adapted lineages, but the genes that are functionally related to thermal adaptation may be difficult to identify. We here used a bioinformatics genome-mining approach to predict and identify functions for suitable candidate markers for thermal adaptation in the chicken. We first established a framework of candidate functions for such markers, and then compiled the literature on genes known to or adapt to the thermal environment in different lineages of vertebrates. We then identified them in the genomes of human, chicken, and the lizard Anolis carolinensis, and established a functional genetic interaction network in the chicken. Surprisingly, markers initially identified from diverse lineages of vertebrates such as human and fish were all in close functional relationship with each other and more associated than expected by chance. This indicates that the general genetic functional network for thermoregulation and/or thermal adaptation to the environment might be regulated via similar evolutionarily conserved pathways in different vertebrate lineages. We were able to identify seven functions that were statistically overrepresented in this network, corresponding to five of our originally predicted functions plus three unpredicted functions. We describe this network as multimodal: central regulator genes with the function of relaying thermal signal (1), effect genes with different cellular functions, namely (2) lipoprotein metabolism, (3) membrane channels, (4) stress response, (5) response to oxidative stress, (6) muscle contraction and relaxation, and (7) vasodilation, -constriction and regulation of blood pressure. This network constitutes a novel resource for the study of thermal adaptation in the closely related nonavian reptiles and other vertebrate 
ectotherms.

PeerJ reviewing PDF | (v2014:04:2045:2:0:NEW 15 Aug 2014) 


\author{
Katharina C. Wollenberg Valero ${ }^{1 *}$, Rachana Pathak $^{1}$, Indira Prajapati ${ }^{1}$, Shannon Bankston ${ }^{1}$, \\ Aprylle Thompson ${ }^{1}$, Jaytriece Usher ${ }^{1}$, Raphael D. Isokpehi ${ }^{1}$ \\ ${ }^{1}$ College of Science, Engineering and Mathematics, Bethune-Cookman University, 640 Dr. Mary \\ McLeod Bethune Blvd, Daytona Beach, FL 32114, USA. \\ * To whom correspondence may be addressed. \\ Katharina C. Wollenberg Valero \\ College of Science, Engineering and Mathematics, Bethune-Cookman University, 640 Dr. Mary \\ McLeod Bethune Blvd, Daytona Beach, FL 32114, USA \\ (386) 481-2682 \\ E-mail: valerok@cookman.edu
}




\section{Introduction}

2 The human-induced climate change has recently fueled a renewed interest in the study of thermal

3 adaptation (Angilletta, 2009; 2012). Temperature affects animals primarily via its effects on

4 biochemical reaction rates (Hochachka \& Somero, 2002). Tropical terrestrial ectotherms such as

5 lizards of the genus Anolis provide an excellent model group for the quantitative study of thermal

6 adaptation to changing climatic conditions as we expect them to show an early, rapid response

7 (Tewksbury, Huey \& Deutsch, 2008; Deutsch et al., 2008; Huey et al., 2009). In order to

8 understand the sum of effects of climate change on the fitness of organisms, and to create

9 predictive models it is necessary to incorporate information on phenotype, physiology and

10 evolutionary processes at the genomic level (Sears \& Angilletta, 2001; Seebacher \& Franklin

11 2012). While behavioral and physiological responses to thermal changes are well studied, the

12 exact molecular mechanism by which these responses are generated is still little understood. In

13 the age of genomics, the next logical step is to integrate information from adaptive genomic

14 markers with measures of physiological performance and selection, and to relate evolving

15 genomic regions to physiological performance, in order to identify the pathways under which

16 organismal responses to thermal changes are generated. Previous studies of adaptation have

17 compared genomic divergence between populations adapted to differential environmental

18 conditions (Hohenlohe et al., 2010; 2012; Hemmer-Hansen et al., 2013; Hübner et al., 2013). The

19 challenge with this approach is, that in addition to genomic adaptations to temperature

20 differences, genomic regions of high divergence also can reflect divergence unrelated to this

21 particular environmental variable, for example differences in sensory environment (Gunter et al.,

22 2011). To facilitate finding the connections between adaptive genomic regions and quantitative

23 traits in relation to thermal adaptations, information on such adaptive pathways derived from the

24 existing literature and online databases can be mined across evolutionary lineages, in order to

25 identify possible candidate markers for thermal responses in non-model organisms. While 
26 candidate markers that correlate with thermal adaptation or plasticity could likewise be

27 influenced by other underlying selective pressure, they provide a solid basis for the study of

28 functional associations of markers diverging in population genomic studies. Based on literature

29 mining of candidate markers related to thermal adaptation across evolutionary lineages, we

30 construct functional genetic networks to determine functional associations between them. This

31 will facilitate the discovery of genetic and cellular pathways relevant to thermal adaptation in

32 ectothermic, vertebrate non-model organisms.

33 The organismal response to deviations from the thermal optimum can be subdivided in two

34 categories based on their temporal dimension and potentially associated differences in the 35 underlying molecular regulatory mechanisms. These are: (i) plasticity, which is the short-term 36 response to thermal change and (ii) adaptation, which is a result of thermal change acting as an

37 agent of natural selection on a population. Potential underlying mechanisms include hormonally 38 regulated short-term responses, changes in regulatory pathways allowing permanent up39 regulation of gene expression, and changes in sequences of genes and regulatory elements. In a 40 current literature review, Urban, Richardson \& Friedenfels (2014) found that plasticity played an 41 important role in promoting phenotypic changes in response to short-term climate variation of 42 ectothermic vertebrates (amphibians and reptiles). In that study, adaptive responses to short-term 43 (human-mediated) climate change were not found, but climate adaptation occurred along spatial 44 gradients, representing standing and historically more stable climatic clines. The influence of 45 mechanisms allowing plastic responses in a population on adaptive evolution to more 46 permanently altered thermal environment in amphibians and reptiles is unclear yet (Urban, 47 Richardson \& Friedenfels, 2014). However, it is thinkable that evolutionary conserved molecular 48 mechanisms and pathways can provide these short-term changes of body physiology ). Especially 49 when combined with standing variation in a population, this might consider an important raw 
50 material for adaptation to occur (West-Eberhardt, 2003). For example, plasticity has been

51 predicted to allow birds to adapt to climate change (Vedder, Bowhuis \& Sheldon, 2013). Known

52 molecular genetic markers that have been identified in having a function in plastic response or

53 adaptation in any clade therefore serve as an ideal basis to identify functional genetic pathways of

54 thermal adaptation.

55 Mammals and birds are most commonly referred to as endotherms, as they are able to generate

56 body heat from metabolic processes, with a set-point optimal temperature (homeothermy). Other

57 vertebrate lineages, fishes, amphibians and reptiles, are referred to as ectotherms since they

58 usually do not maintain a stable body temperature (heterothermy). However, exceptions from this

59 consensus are numerous: heterothermy in the form of torpor (hibernation) is present in many

60 endotherms (e.g., Madagascan Lemurs, Dausmann et al, 2004; birds, McKechnie \& Lovegrove,

61 2002).

62 Endotherm mammals generate heat (nonshivering thermogenesis) by lipolysis (breaking up fat in

63 the adipose tissue). During cold exposure, the neurotransmitter noradrenaline is released to brown

64 adipose tissue (BAT) where lipolysis takes place (Leppäluoto et al., 2005). Free fatty acids open a

65 mitochondrial proton channel (Thermogenin, coded by the UCP1 gene), which results in protons

66 returning to the intermembrane space and inhibiting ATP synthesis (uncoupling). Instead, energy

67 is lost as heat (facultative or adaptive thermogenesis, reviewed in Leppäluoto et al., 2005). BAT

68 is the thermogenic component of the sympathethic nerve system. In ectotherms, it is not known

69 which mechanisms are used to maintain body heat except for behavioral thermoregulation. BAT

70 is absent in marsupials and monotremes (Hayward \& Lisson, 1992). Heat generation in

71 endotherms is related to lipid transport and often expressed in BAT. In ectotherms, BAT is not

72 present, and the role of thermoregulation as associated with the lipoprotein metabolism is not

73 clear. Endotherm birds also use the uncoupling mechanism but since BAT is absent in them, the 
74 primary location for nonshivering thermogenesis is the skeletal muscle (reviewed in Leppäluoto 75 et al., 2005).

76 For ectotherms, the predominant view is that mostly morphological or behavioral adaptations 77 exist to enable heat or cold plasticity and adaptation. These include convection (heat loss by 78 increasing blood flow close to the body surface, conserving heat by decreasing blood flow close 79 to the body surface, Bartholomew \& Tucker, 1963), conduction (moving close to a surface with 80 warmer/colder temperature), radiation (minimizing/maximizing sun exposure), and insulation 81 (altering the surface/volume ratio, e.g., by plumage). Behavioral thermoregulation is undoubtedly

82 the main mechanism to buffer changes in thermal environment (Sunday et al., 2014). However, 83 present species distributions of ectotherms sometimes span large ranges in thermal environments, 84 and local populations do show adaptations to these local thermal conditions. Genetic mechanisms 85 must therefore exist that explain such local adaptations. For example, many amphibians and 86 nonavian reptiles (in the following: reptiles) are found in diverse thermal environments (Addo87 Bediako, Chown \& Gaston, 2000), and several studies report examples of adaptation to such 88 different thermal environments (e.g., Munoz et al., 2013). The purpose of this paper is to 89 elucidate possible genes and functional pathways in which thermal adaptation takes place beyond 90 behavioral thermoregulation in vertebrate ectotherms.

91 Heterothermy has been proposed to be plesiomorphic originating in the common ancestor of birds 92 and mammals (putatively a therapsid reptile). If this is the case, it would mean that the same 93 pathways for thermal plasticity and adaptation that are known from birds and mammals are likely 94 to also operate in extant reptiles (reviewed in Grigg, Beard \& Augee, 2004). Other studies found 95 that ectotherms seem to be able to regulate their internal temperature set-points at least to a small 96 degree. For example, Anolis lizards are able to acclimate their critical thermal minimum in the 97 course of only a few days (CTmin, Petersen, Gleeson \& Scholnick, 2003; Kolbe et al., 2014), as 
98 do alligators (Guderley \& Seebacher, 2011). Other adaptations to diverse thermal environments

99 include for example the presence of cryoprotectants in the blood stream (such as glycerol, in 100 fishes, frogs, Zimmerman et al., 2007; Honer et al., 2013). Thermal plasticity and adaptation in

101 reptiles might thus be regulated via the same genes and cellular pathways that respond to thermal

102 environmental changes in other lineages such as boid snakes, birds and mammals. Based on this

103 information, we expect candidate markers for thermal adaptation (and, possibly, plasticity) in

104 ectotherms such as Anolis lizards, to fall into one of five functional categories:

105 1. Associated with the lipoprotein metabolism/nonshivering thermogenesis.

106 2. Associated with membrane channels controlling water loss/retention or cryoprotectants.

107 3. Associated with short-term stress response.

108 4. Associated with phenotypic or phenological changes arising as a consequence to thermal change, e.g pigmentation associated with thermoregulation.

110 5. Associated with thermal signal transduction

111 In this paper, we test the hypothesis that previously identified candidate genes for thermal 112 adaptation can be grouped into these proposed functional categories and consequently are

113 functionally connected via gene interaction pathways. To test this hypothesis, we integrate

114 literature searches of known markers for thermal adaptation with functional association

115 modelling, in order to identify genes that have found to be under selection (adaptation), or are

116 known to show a short-term response (plasticity) to changes in the thermal environment.

117 Candidate genes are retrieved from studies performed in any vertebrate including humans,

118 lizards, chicken, frog and fish. We identify functional interactions between them using the

119 chicken genome as a model. Since the chicken is the model organism closest related to nonavian

120 reptiles, we discuss the possible relevance of candidate genes for them (especially Anolis lizards).

121 A flowchart of the workflow of this paper is presented in Box 1.

\section{Materials \& Methods}


123 Markers and cellular pathways that are known to be related to thermal plasticity or adaptation in

124 any vertebrate lineage were identified via literature searches in PubMed

125 (http://www.ncbi.nlm.nih.gov/pubmed), GeneCards (http://www.genecards.org/), and ENSEMBL

126 (http://www.ensembl.org/index.html) in March 2014, and matched to gene identifiers of the

127 Homo sapiens (human), Gallus gallus (chicken), and Anolis carolinensis (lizard) genomes. The

128 search terms for finding candidate genes were "thermal adaptation/tolerance", "heat

129 adaptation/tolerance", "cold adaptation/tolerance", and "climate adaptation". To avoid circularity

130 of our argument, no function was used as search term. Supplementary Table 1 shows a list of the

131 identified candidate markers with their location on the Anolis carolinensis genome, and a list of

132 functions of the human orthologs of these candidate genes retrieved from RefSeq

133 (http://www.ncbi.nlm.nih.gov/refseq/) via GeneCards. Functional relationships that are known or

134 predicted between encoded proteins of the potential candidate genes were determined via the

135 STRING algorithm (V. 9.1) embedded in CYTOSCAPE (V. 3.1.0, Shannon et al., 2003) for

136 human and chicken. CYTOSCAPE visualizes functional interactions of genes by applying a

137 network-based algorithm based on molecular triangulation (Krauthammer et al., 2004).

138 Functional pathways between genes were inferred by (i) interologs (= protein interaction across

139 evolutionary lineages) mapping, (2) curator inference, (3) predictive text mining, (4)

140 phylogenetic profile, (5) experimental interaction detection. Not all functional genetic

141 interactions that are known for humans, are already known for the chicken yet. Four additional

142 functional connections that connect parts of the candidate networks in humans but not in the

143 chicken, weretherefore manually added to the algorithm-generated chicken networks in

144 CorelDraw (V.X6). It is important to point out that these four connections are hypothetical until

145 further evidence is available.

146 In order to test whether our predicted gene functions are gene functions which are more common 147 than expected by random functional interactions (called statistically overrepresented Gene 
148 Ontologies, GO), we applied the Hypergeometric test using the BiNGO plugin to CYTOSCAPE

149 (Maere et al., 2005). BiNGO maps the predominant functional themes of a given gene set on the

150 GO hierarchy and applies the Hypergeometric test (Maere et al., 2005). The Benjamini \&

151 Hochberg False Discovery Rate (FDR) correction (Benjamini \& Hochberg, 1995) was applied for

152 multiple tests.

153 To test the hypothesis that candidate genes are indeed more strongly associated with candidate

154 functions than associated genes not initially postulated as candidates, a randomization approach

155 was used. A list of 395 genes that were the closest neighbors (protein-coding genes with known

156 function) of candidate genes in the candidate gene functional network was established as a new

157 dataset. From this list of neighbor genes functionally associated with candidate genes but not

158 initially postulated as candidate genes, we extracted 50 random subsets of 44 genes each

159 (corresponding to the initial number of candidate genes), and calculated functional networks from

160 them. Network statistics were then computed with the NetworkAnalyzer function in

161 CYTOSCAPE from both the candidate gene network and the random networks. Ozgur et al.

162 (2008) found that such centrality measures can significantly predict disease association for

163 candidate genes in a network. We tested for difference in the metrics clustering coefficients,

164 heterogeneity, network density, and average node closeness centrality between randomized

165 networks and candidate gene network.

166 To test whether candidate functions are more present in the candidate network than in the random

167 networks, BiNGO was used to calculate significantly overrepresented Gene Ontologies from the

168 random networks. A Mann-Whitney U Test (with continuity correction) was performed in

169 STATISTICA (StatSoft, Tulsa, OK) to test for differences in presence/absence of candidate

170 functions of genes and gene interaction groups across the two comparison groups (random

171 neighbors and candidate genes). 
172 An interactive web-based visual analytics resource was developed to facilitate data exploration of

173 the gene list for knowledge-building on thermal adaptation in vertebrates. The web-resource is

174 available at: https://public.tableausoftware.com/views/thermal_adapt/gene_list.

\section{Results and Discussion}

17631 of our initial list of 44 candidate markers were retrieved in the chicken genome. All these

177 markers were functionally related, by association either through the CYTOSCAPE software, or

178 by manual association after comparisons of functional pathways with the human equivalent of the

179 functional network. The chicken network is shown in Figures 2, 3, and 4. A more detailed version

180 of the large functional network (Figure 2) is shown in Supplementary Figure 1.

181 To test whether candidates are in closer functional association with each other than similar genes

182 not proposed as candidates, we compared clustering coefficients, heterogeneity, network density,

183 and average node closeness centrality between randomized networks and candidate gene network

184 (Figure 5). The network clustering coefficient is a measure of how well nearest neighbors of

185 candidate genes are connected. The candidate network was significantly less clustered than the

186 randomized neighbor networks, hinting at discrete functional pathways instead of genes shared

187 across different adaptive functions in the candidate gene network. The network heterogeneity

188 describes the tendency of a network to contain hub nodes (Dong \& Horvath, 2007). Despite that

189 we identified genes that function in thermal signal relay and stress response, this measure was not

190 significantly different from the randomized neighbor networks. Network density describes the

191 propensity of network nodes to be isolated vs. forming a clique (being more functionally

192 associated). The candidate gene network was significantly denser than the random neighbor

193 networks, indicating closer functional association between candidate genes. Closeness centrality

194 is a measure of how fast information spreads from a given node to other reachable nodes in the 
195 network (Newman, 2003). The closeness centrality averaged over all nodes was significantly

196 higher in the candidate gene network, showing that functional associations among candidate

197 genes were higher than expected by chance in functionally associated non-candidate genes.

19823 of the 31 markers in the candidate gene network (Figures 2-4) were represented as having a

199 significantly overrepresented GO in the network (Table 1). Among our five predicted functions 200 for these candidate markers, four were retrieved as overrepresented GOs (Table 1).. The only 201 predicted function of candidate markers that was not retrieved as overrepresented GO was that of 202 phenotypic change associated with thermal change, as in the example of pigmentation associated 203 with thermoregulation in reptiles. The frequently studied MC1R gene that is associated with such 204 pigmentation and that was in our list of potential candidate markers retrieved from the literature, 205 could not be retrieved in the chicken network, nor could it be located in the Anolis carolinensis 206 genome. Instead, the MC2R-4R genes were represented in the network, but not retrieved as a 207 significantly overrepresented GO and are discussed below. Another group of genes that formed 208 part of the candidate gene list and functional network but were not overrepresented GOs is the 209 AQP gene family coding for water and glycerol channels. One possible reason for this is that 210 maybe their relative number in the network is too small, or the functions in the chicken are still 211 understudied or remain to be annotated, and we here flag them for further study. Three additional 212 statistically overrepresented GO functions retrieved by BiNGO were not among our functional 213 predictions. These additional, previously unpredicted functions related to thermal plasticity and 214 adaptation are (Table 1$)$ :

215 6. Response to oxidative stress

216 7. Muscle contraction and relaxation, and muscle development

217 8. Vasodilation, vasoconstriction, blood circulation and blood pressure regulation 
218 The genes providing a response to oxidative stress might be associated with the fact that low

219 temperatures cause hypoxia (Petersen, Gleeson \& Scholnick, 2003), while both high and low

220 temperatures cause oxidative stress (free oxygen radicals in the cell). Freeze-tolerant reptiles

221 display tolerance for hypoxia and antioxidant defense (Storey, 2006). For example, freeze

222 responsive genes in turtles code for (a) proteins involved in iron binding, (b) enzymes of

223 antioxidant defense, and (c) serine protease inhibitors, that all are functionally related to

224 providing oxygen and glucose to tissues under hypoxia (Storey, 2006).

225 The response to thermal changes associated with genes involved in muscle contraction and

226 relaxation clearly points at the connection between nonshivering thermogenesis in birds, and

227 ectothermic shivering thermogenesis, both processes being located in the muscle. Shivering

228 thermogenesis is the only facultative way of generating body heat and is universally found in

229 mammals and birds, as well as some reptiles (boid snakes). In shivering thermogenesis, body heat

230 is generated in the skeletal muscles by neuronally controlled muscle contractions (Hutchison,

231 Dowling \& Vinegar. 1966; reviewed in Grigg, Beard \& Augee, 2004). This process can elevate

232 body temperature in brooding female pythons up to six degrees Celsius (Brashaers \& DeNardo,

233 2013) and proves that endo-and ectothermy are not perfectly delimited categories.

234 Vasodilation, vasoconstriction, blood circulation and blood pressure regulation have been

235 observed to be important mechanisms in reptiles related to convection. Heat loss in reptiles is

236 accomplished by increasing blood flow close to the body surface, versus conserving heat by

237 decreasing blood flow close to the body surface (Bartholomew \& Tucker, 1963). Genes

238 associated with vasodilation and -constriction can regulate such a mechanism. Although

239 vasoconstriction was not among the significantly overrepresented GO, one of the candidate genes

240 (EDN1) is functionally associated with vasoconstriction in humans.

241 To test whether significantly overrepresented GO that correspond to candidate functions were 242 more present in the candidate gene network than in the random neighbor networks, we tested for 
243 presence versus absence of candidate functions in both test groups. After removal of redundant

244 functions per gene/interaction group (remaining $\mathrm{N}=3048$ ), the candidate gene network recovered

245 significantly more genetically overrepresented candidate functions than the random networks.

246 This results corroborates the finding that the association between candidate genes and postulated

247 functions is significantly higher than expected by chance in functionally associated non-candidate

248 genes (Table 2). In the following sections candidate genes that are represented in our functional

249 genetic network and potentially relevant for genetic adaptations to thermal changes are discussed.

250 Functions that are not cited in a reference correspond to functions of the human gene ortholog/s

251 obtained from RefSeq and deposited in Supplementary Table 1.

\section{Candidate markers within the lipoprotein-metabolism associated functional network}

253 The largest functional network that was recovered from the chicken genome using search strings

254 for human gene names, fall into several functional categories (Figure 2). Several of these

255 candidate markers have been identified in a study of SNPs in the global human population with

256 respect to their variation with global climate (Hancock et al., 2008). The study recovered several

257 SNPs within genes for common metabolic disorders that were associated with latitudinal

258 variation (FABP2), summer duration (CD36, DSCR1, MAPK14, PON1, SOD1, CETP, EGFR,

259 and NPPA) and winter duration (RAPTOR, UCP3, LPA, MMRN1, EPHX2, LEPR, MAPK1,

260 Hancock et al., 2008). However, the Hancock et al. (2009) study did not include network-based

261 visualization, so that the functional relationships of these markers among each other were not

262 recovered. We here discuss these and other markers based on their functional associations within

263 the chicken candidate network. The numbers of sub-headings correspond to the network parts 
264 described in Figure 2, and to the function of that part of the network (denoted "GO" if 265 significantly overrepresented).

2661 -Signal relay (GO), stress response (GO), Lipoprotein metabolism (GO). MAPK1 and

267 MAPK14 are genes that are important for several cellular signaling pathways, and their sequence 268 variation is related to winter adaptation by humans (Hancock et al., 2008). Human MAPK14 269 furthermore is specifically activated in response to environmental stresses.

2702 -Signal relay $(G O)$. The EGFR protein is a membrane receptor for epidermal growth factors. It 271 is functionally related to seven other candidate markers in our network, and could therefore 272 represent a functional hub for the relay of thermal signaling. In humans, it is associated with lung 273 cancer which relates it to respiration.

2743 - Lipoprotein metabolism. The LEPR gene product (the leptin receptor), has been shown to 275 significantly vary with the duration of winter in the human population, which represents an 276 adaptation to cold environments (Hancock et al., 2008). According to Hancock et al. (2008), 277 LEPR is a strong candidate gene due to its involvement in a thermogenesis pathway that is 278 inducible in skeletal muscle in the mouse model (Dulloo, Seydoux \& Jacquet, 2002; 2004;

279 Hancock et al., 2008), bearing similarities to nonshivering muscle-associated thermogenesis in 280 birds and shivering muscle associated thermogenesis in birds and reptiles. LEPR is associated 281 with EGFR, MAPK1 and, via POMC, with five other markers functionally associated with 282 thermogenesis.

2834 -Vasodilation (GO), blood circulation (GO), blood pressure regulation (GO). POMC, the gene

284 for the pro-opiomelanocortin receptor, undergoes tissue specific posttranslational processing. The 285 functions of the resulting peptides in humans include maintenance of adrenal weight, 286 inflammatory pain and energy homeostasis, melanocyte stimulation, and immune modulation. In 287 carp fish (Cyprinus carpio) that is a eurytherm species persisting over a wide range of 288 temperatures, two POMC genes are present. Their expression levels have been found to alternate 
289 with temperature (24 versus 9 degree Celsius; Arends et al., 1998). An interesting experiment 290 performed by Chuang et al. (2004) showed that human POMC gene introduced via plasmids into 291 muscles of arthritic mice alleviated both thermal hypersensitivity and paw swelling symptoms.

292 Swelling hints at its involvement in vasodilation, which was a significantly overrepresented GO 293 for this gene. POMC mutations in humans are associated with early onset obesity and linked to 294 leptin concentrations (Delplanque et al., 2000). This also corroborates the role of POMC in 295 thermal signal relay and its putative functional association with the lipoprotein metabolism 296 (LEPR gene). Another candidate gene that was among our search terms was MC1R (the 297 melanocortin 1 receptor). The interaction of MC1R and POMC expression (a hormone that can 298 stimulate the MC1R) is known, with available amplification primers available for several species 299 of reptiles and amphibians (e.g., Duchrest et al., 2014). POMC signals to the melanocortin 300 receptor lead to the movement or permanent positioning of melanin through layers of the skin, 301 causing changes in pigmentation as well as pattern phenotypes. Since skin darkening is a major 302 component of thermoregulation in reptiles (increasing the absorbed sun radiation), this gene 303 complex is an ideal candidate gene pair to study thermal plasticity and adaptation (Rosenblum, 304 Hoekstra \& Nachman, 2004). However, this gene was not retrieved in the chicken network 305 (despite supposedly being present on chromosome 11, Supplementary Table 1), and also was not 306 found in the Anolis carolinensis genome. Instead, among the genes directly interacting with 307 POMC in the chicken functional network were MC2R, MC4R, and MC5R. MC5R could not be 308 found in the lizard genome, but MC2R and MC4R have orthologs in the lizard genome, and were 309 therefore post-hoc included into our list of candidate genes (Supplementary Table 1). MMRN1 is 310 another candidate marker with direct functional link to POMC that has been shown to vary with 311 winter duration in the global human population (Hancock et al., 2008). It encodes for a large 312 soluble protein, multimerin, found in platelets or the endothelium of blood vessels. It may play a 313 role in cell adhesion. A paralog, MMRN2 was identified as providing adaptation to high altitude 
314 in Yak (Bos mutus, Quiu et al., 2012). It functionally relates to AHSG, as well as to the ADORA 315 gene network.

3165 - Lipoprotein metabolism (GO), stress response (GO), signal relay. STUB1 is involved in the

317 degradation of misfolded proteins, and can modulate the activity of several heat shock proteins. It

318 is involved in the cellular reaction cascade that responds to heat stress. Its involvement in thermal 319 plasticity and adaptation in non-mammalian vertebrates has not been studied yet.

3206 -Vasoconstriction, oxidative stress response. EDN1 encodes the endothelin-1 peptide in 321 humans which is important in vasoconstriction. It is involved in hypoxic pulmonary 322 vasoconstriction where pulmonary arteries constrict in the presence of hypoxia (low oxygen 323 levels which leads to redistribution of blood flow to better-ventilated areas of the lung, which 324 increases the total area involved in gaseous exchange. It has been demonstrated to be involved in 325 high altitude adaptation (Savourey et al., 1998), for example in vascular adaptation to high 326 altitudes in pregnancies (Moore et al., 2004). Length variants in endothelin-1 have been shown to 327 be associated with altitudinal acclimation as well (Rajput et al., 2006). The EGLN1 marker is 328 another candidate gene related to the functional association with oxygen transport. In humans, 329 adaptations in this marker have been found in populations that inhibit high altitudes, i.e., 330 experience reduced oxygen levels (Aggarwal et al., 2010; Peng et al., 2010; Xiang et al., 2013;

331 Mishra et al., 2013). EGLN1 is related to EPAS2, which in humans encodes a transcription factor 332 involved in the induction of genes regulated by oxygen, which is induced as oxygen levels fall.

3337 - Signal relay (GO). MRAS (also called R-Ras3) is of unknown physiological role in humans 334 (Labunskay \& Meiri, 2006). In our functional network it was placed as relaying the signal from 335 another gene, EGFR, and from MAPK1 via the JUN gene which is also part of our predicted 336 thermal signal relay cascade. A previous study has shown, that it is involved in the establishment 337 of thermal control in the chicken embryonal brain. Both heat and cold induce gene expression of 
338 MRAS and of JUN (Labunskay \& Meiri, 2006), corroborating its putative function as a thermal

339 signal relay gene.

3408 - Stress response (GO), oxidative stress response (GO), Signal relay (GO), Muscle contraction

341 and relaxation $(G O)$, vasodilation $(G O)$. SOD1 codes for superoxide dismutase, an enzyme that

342 can reduce the concentration of free superoxides in the cytoplasm. Oxidative stress is thought to

343 increase with deviation from the thermal optimum in fish (Vinagre et al., 2012). A study in

344 shrimp has shown that the shrimp equivalent of the SOD1 gene is upregulated under high heat

345 stress, putatively via heat shock proteins (Sookruksawonga, Pongsoombona \& Tassanakajon,

346 2013). We could show in this contribution that SOD1 is indeed functionally related to the HSP

347 gene family (see HSP discussion below). SOD1 being involved in short-term cell protection in

348 response to thermal stress, but being controlled by the same regulatory pathway (MAPK1 via

349 STUB1) which relays the signal for thermoregulation and is adaptive to thermal environmental

350 changes, indicates that there is a functional relationship between plasticity and adaptation, and

351 furthermore to its evolutionary conserved function as proven by functional similarity in shrimp,

352 fish and humans.

3539 - Stress response (GO). UNG codes for two alternatively spliced DNA Uracil glycosylases that

354 are involved in mismatch repair of Uracil in DNA. The UNG gene is functionally related to

355 SOD1 which itself is influenced by the Chaperone STUD1. Previous studies have found UNG to

356 be cold-adapted in Atlantic cod fish with an increased catalytic efficiency and thermoliability as

357 compared to UNG adapted to medium temperatures (Lanes et al., 2000, Olufsen, Smalas \&

358 Brandsdal, 2008; Assefa et al., 2012).

35910 - Stress response, response to oxidative stress, Lipoprotein metabolism. AHSG is functionally

360 related to MMRN1 and PLG. AHSG is expressed in the human liver, secreting the AHSG

361 glycoprotein. It also is expressed in adipose tissue in humans, and is involved in the 362 predisposition to obesity (Dahlman \& Arner, 2007). It is a part of the lipoprotein metabolism, and 
363 interesting as a candidate gene due to its functional association with other markers. The HPSE

364 gene codes for heparanase, which is hypothetically related to AHSG via the human NPS gene.

365 Heparanase is involved in the constitution of the extracellular matrix and cell-cell interactions.

366 Adaptive evolution of heparanase has led to a unique splice variant in the rodent Spalax

367 ehrenbergi, which is presumably involved in adaptation to hypoxia, or metabolic stress in general

368 (Nasser et al., 2005).

369 11-13 - Lipoprotein metabolism (GO), water channel/glycerol as cryoprotectant (GO), signal $370 \operatorname{relay}(G O)$.

371 CETP is a marker positively associated with adaptation to summer duration in humans (Hancock 372 et al., 2008). Single Nucleotide polymorphism frequencies within the human FABP2 gene, 373 encoding a protein that binds fatty acids, have been shown to be significantly varying with 374 latitude of the global human population (Hancock et al., 2008). FABP2 variants are adaptive to 375 thermal changes in terms of increasing fat storage in cold environments (Hancock et al., 2008).

376 LPL (lipoprotein lipase) is an enzyme involved in the breakdown and uptake of lipoprotein 377 triglycerides related to the lipoprotein metabolism which in the mammal BAT is a main pathway 378 for nonshivering thermogenesis. Jensen et al (2008) found that transgenic mice who 379 overexpressed human LPL in their skeletal muscle displayed enhanced cold tolerance and 380 thermogenesis by increased fat oxidation. Jensen et al. (2008) suggested that this response was 381 achieved by gene expression in skeletal muscle - This phenotype resembles that of birds which 382 exhibit a thermogenic response to cold temperatures via their skeletal muscles. Consequently, the 383 LPL gene is a good candidate to study non-BAT associated thermogenesis in birds, and 384 potentially in vertebrate ectotherms. CD36 varies significantly in humans with the intensity of 385 summer (Hancock et al., 2008). It encodes for the thrombospondin receptor and binds to oxidised 386 LPL and might function as a regulator or transporter of fatty acids. Its intermediate position in the 387 FABP2 $\square$ LPL $\square$ CD36 $\square$ UCP functional connection points at its involvement in BAT-associated 
388 thermogenesis. The Uncoupling Protein 3 gene is the fourth component of the functional network 389 constructed with the known candidate markers for thermal adaptation, the UCP gene. Numerous 390 studies have identified uncoupling proteins (also called mitochondrial anion carrier proteins) as 391 central players in mammalian BAT-located thermogenesis. In endotherms, the BAT-expressed $392 \mathrm{UCP}$ is UCP1. UCP3 has tissue-specific transcription initiation upstream of the SM-1 (major 393 skeletal muscle site, Esterbauer et al., 2000). This associates it with skeletal muscle-associated 394 nonshivering thermogenesis, as it has been found in previous studies from both mammals and 395 birds (e.g., Klingenspor, 2003). For example, Teulier et al. (2010) found that ducklings reared 396 under lower ambient temperature were cold-acclimated by upregulation of UCP, and had a higher 397 capacity for muscle associated nonshivering thermogenesis. King penguins have been shown to 398 respond to cold stimuli with thermogenesis both by uncoupling oxidative phosphorylation in the 399 mitochondria of the skeletal muscle by expressing UCP and increased proton transport activity of 400 the adenine nucleotide translocase (Talbot et al., 2004). In this regard the candidate gene mt401 ATP6 coding for mitochondrial ATP-Synthase might be of interest - but this marker was not 402 connected with the general interaction network of the chicken. Besides plasticity, UCP has been

403 found to have undergone adaptive evolution: UCP orthologs are present in all vertebrate lineages 404 including fishes, and UCP1 has undergone rapid diversification in ancestral eutherian mammals 405 (Saito, Saito \& Shingai, 2008) associated with BAT-associated thermogenesis. However, the gene 406 duplication events leading to the three paralogs UCP1, UCP2, and UCP3 were older than the 407 diversification of eutherians (Saito, Saito \& Shingai, 2008), as confirmed here by the presence of 408 UCP3 in the chicken functional network.

\section{Candidate markers within the Heat Shock Gene functional Network}

410 Stress response (GO), signal relay (GO), Muscle contraction and relaxation (GO). Heat shock 411 proteins (Hsps) are molecular chaperones that are universally present in all organisms and carry 
412 out a well characterized stress response: HSPs protect proteins that denature under heat stress

413 from aggregating (Tavaria et al., 1996). The Heat shock protein network could manually be

414 linked to the large functional network via HSPA1 and HSPA4 being functionally connected to

415 MRAS and SOD1. Narum et al. (2013) investigated the heat shock response in montane and

416 temperate strain of fish and found high induction of heat shock proteins in the montane strain,

417 which appeared to improve short-term survival during first exposure to high water temperatures.

418 However, this was not associated with an increased long-term survival of fish under thermal

419 stress which underlines the function of the HSP response as being acclimative, not adaptive. In

420 contrast, Garbuz et al (2008) studied HSP gene expression in a family of flies (Diptera:

421 Stratiomyidae), that inhabits extreme environments (including the proximity of volcanoes), and

422 found that HSPs are facultatively upregulated in these flies. This constitutes evidence for

423 evolutionary adaptation occurring in a mechanism geared towards short-term stress response. The

424 HSPA14 gene which encodes the Heat Shock 70kDa Protein 14, is one of these facultatively

425 upregulated HSP genes in Stratiomyidae. LEDGF is a regulatory protein with the capability to

426 upregulate general transcription, and specifically the transcription of HSPs under stress (thermal

427 or oxidative, Sharma et al., 2000). It is hypothetically linked to the HSP functional network via

428 the human SUMO gene (the chicken equivalent could not be identified). HSP47/SERPINH1 was

429 found to be the most commonly upregulated gene that trout fish express in gills under heat stress

430 (Rebl et al., 2013)

431 Candidate markers within the Aquaporin Functional Network, and their association with 432 water homeostasis

433 Water channels, cryoprotectants transport. Another group of candidate markers can be found 434 within the evolutionary ancient Aquaporin gene family coding for membrane proteins that 435 facilitate water and glycerol transport. All genes of the AQP gene family (with the exception of 
436 AQP7) have been found and characterized in non-termoregulating Zebrafish (Tingaud-Sequeria

437 et al., 2010). AQPs transport water, glycerol, and small solutes across membranes which both is

438 important for heat adaptation (evapotranspiration, preventing desiccation) and cold adaptation

439 (Cryoprotectant transport into tissues). In endothermous animals, sweating is a major

440 physiological mechanism of thermal plasticity. It is the process of the excretion of salt and water

441 through sweat glands in order to cool down the body via evaporative cooling. Evaporative

442 cooling is the process by which air temperature is lowered by adding water vapor. AQP5 and

443 AQP3 have been found to be expressed in sweat glands of rats, where AQP3 was expressed in

444 the basal levels of the epidermis, and AQP5 was expressed in sweat glands (Nesjum et al., 2002).

445 Similar evaporative cooling is one of the few known processes of thermoregulation in

446 ectothermic vertebrates such as amphibians and reptiles (Tattersall, Cadena \& Skinner, 2006).

447 Instead of sweat glands, water evaporates here through the mucosa of the mouth, or through the

448 skin. In anuran amphibians, AQP3 is expressed in osmoregulatory organs and has been identified

449 as the site of transepithelial water exit (Suzuki \& Tanaka, 2009). In humans, AQP3 has

450 furthermore found to be involved in glycerol transport in the epidermis (Hara-Chikuma and

451 Verkman, 2008). Suzuki \& Tanaka (2009) speculated that AQP3 expression in the frog epidermis

452 is related to glycerol transport. A known mechanism of cold adaptation in ectothermic vertebrates

453 is the prevention of blood crystallization by blood supercooling, usually by blood glucose,

454 glycogen, or glycerol deposition (reviewed in Constanzo, 2011). Zimmerman et al (2007) found

455 that accumulation of glycerol in frogs during cold acclimation, which is secreted by the liver, was

456 related to expression of aquaporin (including AQP3) gene expression. Consequently, the AQP5

457 gene is a candidate marker to study thermal adaptation - both to heat and to cold - in amphibians.

458 However, so far there is little evidence for cryoprotectants in reptiles (Storey, 2006). Aquaporin-5

459 (AQP5) is a protein that forms water specific channel. Three genes for AQP5 are present in the 460 genome of Anolis carolinensis. In humans, AQP5 are localized and expressed in the secretory and 
461 lachrymal glands, kidney, lungs and nerves. The AQP5 is modified in yak (Bos mutus), a bovine,

462 as adaptation to survival in high altitude (Quiu et al., 2012) that is both characterized by low

463 oxygen as also cold temperatures.

464 Candidate markers within the ADORA Functional Network, and their association with 465 oxygen transport.

466 Signal relay (GO), Muscle contraction and relaxation (GO), Vasodilation, vasoconstriction, 467 blood circulation, blood pressure regulation $(G O)$. Adenosine is an agonistic neurotransmitter 468 present in many vertebrate lineages, including lizards (Michaelidis et al., 2002). In one of the few 469 existing studies demonstrating metabolic thermoregulation in ectothermic vertebrates, Petersen, 470 Gleeson \& Scholnick (2003) found that if oxygen is scarce (less than 10\%), reptiles (Anolis 471 sagrei and Dipsosaurus dorsalis) are able to downregulate their internal body temperature, even 472 in low ambient temperatures. This mechanism has the putative function of protecting the body 473 against ambient hypoxia. After oxygen is available again, the effect will be abolished and body 474 temperature restored to environmental temperature. Administrating an antagonist to the adenosine 475 receptor prevented this alteration of the thermoregulatory set point. Several adenosine receptors 476 exist in vertebrates that are candidate genes to studying this thermoregulatory behavior, encoded 477 by the genes ADORA1, 2A, 2B, 3 (humans and chicken). In Anolis carolinensis, ADORA1 and 478 ADORA2 seem to be duplicated, (Supplementary Table 1), while ADORA2B is not annotated 479 yet, and ADORA3 is potentially absent. Functional Network clustering in the chicken found the 480 ADORA2A and ADORA2B to be functionally linked to ADRB2 via another signal transducer, 481 GNAL. ADRB2 is another candidate marker for thermal adaptation or plasticity: The encoded 482 Beta-2 adrenergic receptor is involved in nonshivering thermogenesis in primates (Tanaka et al., 483 2012), and plays a role in human asthma and obesity (Supplementary Table 1). In humans, both 484 ADRB2 and ADRB3 are involved in lipolysis and thermogenesis and cause differences in energy 
485 expenditure (Girardier \& Seydoux, 1981; Tanaka et al., 2012). Adrenergic-receptor beta3

486 (ADRB3) is located mainly on the surface of visceral and brown adipose cells and promotes

487 lipolysis and thermogenesis by noradrenaline release from the sympathetic nerves stimulated by

488 cold temperature or food consumption. ADRB3 is also present in the Anolis carolinensis genome.

489 This gene therefore is likely linked to the functional theme of Lipoprotein metabolism.

\section{Conclusions}

491 In this study, we constructed a chicken multimodal network of functional relationships from a list

492 of published markers for thermal adaptation in vertebrates. This network was more organized into

493 functional pathways, more functionally associated, and faster in information exchange than

494 expected by chance. While some of the markers might be exclusively related to thermoregulation

495 via BAT in mammals, thermal adaptation and to a certain extent thermoregulation has been

496 shown to act on any other component of this network in other vertebrate lineages. Surprisingly,

497 markers initially identified from diverse lineages of vertebrates such as human and fish were all

498 in close functional relationship with each other. This indicates that the general genetic functional

499 network for thermoregulation and/or thermal adaptation to the environment might be regulated

500 via similar evolutionarily conserved pathways in different vertebrate lineages. We were able to

501 identify seven functions that were statistically overrepresented in this network, corresponding to

502 five of our originally predicted functions plus three unpredicted functions. We describe this

503 network as multimodal: central regulator genes with the function of relaying thermal signal (1)

504 effect genes with different cellular functions, namely (2) lipoprotein metabolism, (3) membrane

505 channels, (4) stress response, (5) response to oxidative stress, (6) muscle contraction and

506 relaxation, and (7) vasodilation, -constiction and regulation of blood pressure. Behavioral

507 thermoregulation and distribution area shifts are expected to be the primary response of

508 vertebrate ectotherms to changes in the thermal environment. In addition, the functional genetic 
509 network established herein provides a new resource for the study of adaptive pathways that exist

510 beyond plastic responses to thermal environmental change in vertebrate ectotherms via

511 experimental or comparative genomic studies. Further research should be directed towards

512 verifying thermal adaptation in candidate markers and towards investigating the genetic basis of

513 thermoregulatory behavior, in order to obtain a comprehensive understanding of the functional

514 genetic basis of thermal adaptation in vertebrate ectotherms.

\section{Acknowledgements}

516 We thank the Bethune-Cookman University Biology and Chemistry faculty members as well as

517 Academic Affairs for their continued efforts in promoting undergraduate research excellence, and 518 for helpful discussions.

\section{References}

520 Addo-Bediako A, Chown S L, Gaston KJ. 2000. Thermal tolerance, climatic variability and

521 latitude. Proceedings of the Royal Society of London, Series B 267:739-745.

522 Aggarwal S, Negi S, Jha P, Singh PK, Stobdan T, Pasha MA, Ghosh S, Agrawal A, Indian

523 Genome Variation Consortium, Prasher B, Mukerji M. 2010. EGLN1 involvement in high-

524 altitude adaptation revealed through genetic analysis of extreme constitution types defined in 525 Ayurveda. Proceedings of the National Academy of Sciences USA 107:18961-18966.

526 Angilletta MJ. 2009. Thermal Adaptation: A Theoretical and Empirical Synthesis. New York:

527 Oxford University Press.

528 Angilletta MJ. 2012. Thermoregulation in Animals. In: Angilletta MJ, ed. Oxford Bibliographies 529 in Physiological Ecology of Animals. New York: Oxford University Press. 
530 Arends RJ, van der Gaag R, Martens GJM, Wendelaar Bonga SE, Flik G. 1998. Differential

531 expression of two pro-opiomelanocortin mRNAs during temperature stress in common carp

532 (Cyprinus carpio L.). Journal of Endocrinology 159:85-91.

533 Assefa NG, Niiranen L, Willassen NP, Smalås A, Moe E. 2012. Thermal unfolding studies of cold 534 adapted uracil-DNA N-glycosylase (UNG) from Atlantic cod (Gadus morhua). A comparative 535 study with human UNG. Comparative Biochemistry and Physiology Part B: Biochemistry 536 and Molecular Biology 161:60-68.

537 Bartholomew GA, Tucker VA. 1963. Control of changes in body temperature, metabolism, and 538 circulation in the Agamid lizard, Amphibolorus barbatus. Physiological Zoology 36:199-218.

539 Benjamini Y, Hochberg Y. 1995. Controlling the false discovery rate: a practical and powerful 540 approach to multiple testing. Journal of the Royal Statistical Society B 57:289-300.

541 Brashaers JA, DeNardo DF. 2013. Revisiting python thermogenesis: brooding Burmese pythons 542 (Python bivittatus) cue on body, not clutch, temperature. Journal of Herpetology 47:440-444.

543 Chuang I-C, Jhao C-M, Yang C-H, Chang H-C, Wang C-W, Lu C-Y, Chang Y-Y, Lin S-H, Huang 544 P-L, Yang L-C. 2004. Intramuscular electroporation with the pro-opiomelanocortin gene in rat 545 adjuvant arthritis. Arthritis Research \& Therapy 6:R7-R14.

546 Constanzo JP. 2011. Extreme cold hardiness in ectotherms. Nature Education Knowledge 3:3.

547 Dahlman I, Arner P. 2007. Obesity and polymorphisms in genes regulating human adipose tissue. 548 International Journal of Obesity (London) 31:1629-1641.

549 Dausmann KH, Glos J, Ganzhorn JU, Heldmaier G. 2004. Hibernation in a tropical primate. $550 \quad$ Nature 429:825-826.

551 Delplanque J, Barat-Houari M, Dina C, Gallina P, Clément K, Guy-Grand B, Vasseur F, Boutin P, 552 Froguel P. 2000. Linkage and association studies between the proopiomelanocortin (POMC) 553 gene and obesity in caucasian families. Diabetologia 43:1554-1557. 
554 Deutsch, CA, Tweksbury JJ, Huey RB, Sheldon KS, Ghalambor CK, Haak DC, Martin PR. 2008.

555 Impacts of climate warming on terrestrial ectotherms across latitude. Proceedings of the

$556 \quad$ National Academy of Sciences USA 105:6669-6672.

557 Dong J, Horvath S. 2007. Understanding network concepts in modules. BMC Systems Biology $558 \quad 1: 24$.

559 Dulloo AG, Stock MJ, Solinas G, Boss O, Montani JP, Seydoux J. 2002. Leptin directly 560 stimulates thermogenesis in skeletal muscle. FEBS Letters 515:109-113.

561 Dulloo AG, Seydoux J, Jacquet J. 2004. Adaptive thermogenesis and uncoupling proteins: a 562 reappraisal of their roles in fat metabolism and energy balance. Physiology \& Behavior. $563 \quad 83: 587-602$.

564 Garbuz DG, Zatsepina OG, Przhiboro AA, Yushenova I, Guzhova IV, Evgen'ev MB. 2008. 565 Larvae of related Diptera species from thermally contrasting habitats exhibit continuous up566 regulation of heat shock proteins and high thermotolerance. Molecular Ecology. 17:4763$567 \quad 4777$.

568 Girardier L, Seydoux J. 1981. Is there a sympathetic regulation of the efficiency of energy 569 utilization? Diabetologia 20:362-365.

570 Guderley H, Seebacher F. 2011. Thermal acclimation, mitochondrial capacities and organ 571 metabolic profiles in a reptile (Alligator mississippiensis). Journal of Comparative 572 Physiology B 181:53-64.

573 Gunter HM, Clabaut C, Salzburger W, Meyer A. 2011. Identification and characterization of gene 574 expression involved in the coloration of cichlid fish using microarray and qRT-PCR 575 approaches. Journal of Molecular Evolution 72:127-137.

576 Grigg GC, Beard LA, Augee MA. 2004. The evolution of endothermy and its diversity in 577 mammals and birds. Physiological and Biochemical Zoology 77:982-997. 
578 Hancock AM, Witonsky DB, Gordon AS, Eshel G, Pritchard JK, Coop G, Di Rienzo A. 2008.

579 Adaptations to climate in candidate genes for common metabolic disorders. PLoS Genetics

$580 \quad$ e32.

581 Hara-Chikuma M, Verkum AS. 2008. Roles of Aquaporin-3 in the Epidermis. Journal of 582 investigative Dermatology 128:2145-2151.

583 Hayward JS, Lisson PA. 1992. Evolution of brown fat: its absence in marsupials and 584 monotremes. Canadian Journal of Zoology 70:171-179.

585 Hemmer-Hansen J, Nielsen EE, Therkildsen NO, Taylor MI, Ogden R, Geffen AJ, Bekkevold D, 586 Helyar S, Pampoulie C, Johansen T, Fishpoptrace consortium, Carvalho GR. 2013. A genomic 587 island linked to ecotype divergence in Atlantic cod. Molecular Ecology 22:2653-2667.

588 Hochachka PW, Somero GN. 2002. Biochemical Adaptation. Mechanism and Process in 589 Physiological Evolution. New York: Oxford University Press.

590 Hohenlohe PA, Bassham S, Etter PD, Stiffler N, Johnson EA, Cresko WA. 2010. Population 591 genomics of parallel adaptation in threespine stickleback using sequenced RAD tags. PLoS $592 \quad$ Genetics 6(2):e1000862.

593 Hohenlohe PA, Bassham S, Currey M, Cresko WA. 2012. Extensive linkage disequilibrium and 594 parallel adaptive divergence across threespine stickleback genomes. Philosophical 595 Transactions B 367:395-408.

596 Honer N, Finatti L, Frisbie J, Goldstein D. 2013. Permeability to glycerol differs in erythrocytes 597 from freeze-tolerant Hyla chrysoscelis and freeze-intolerant Lithobates catesbeianus. FASEB 598 Journal 27 (Meeting Abstract Supplement):937.11.

599 Hübner S, Rashkovetsky E, Kim YB, Oh JH, Michalak K, Weiner D, Korol AB, Nevo E, 600 Michalak P. 2013. Genome differentiation of Drosophila melanogaster from a microclimate 601 contrast in Evolution Canyon, Israel. Proceedings of the National. Academy of Sciences USA. $602 \quad 110: 21059-21064$. 
603 Huey RB, Deutsch CA, Tewksbury JJ, Vitt LJ, Hertz PE, Álvarez Pérez HJ, Garland, T Jr. 2009.

604 Why tropical forest lizards are vulnerable to climate warming. Proceedings of the Royal 605 Society of London B doi:10.1098/rspb.2008.1957.

606 Hutchison VH, Dowling HD, Vinegar A. 1966. Thermoregulation in a brooding female Indian 607 python, Python molurus. Science 151:694-696.

608 Jensen DR, Knaub LA, Konhilas JP, Leinwand LA, MacLean PS, Eckel RH. 2008. Increased 609 thermoregulation in cold-exposed transgenic mice overexpressing lipoprotein lipase in 610 skeletal muscle: an avian phenotype? Journal of Lipid Research 49:870-879.

611 Klingenspor M. 2003. Cold-induced recruitment of BAT thermogenesis. Experimental 612 Physiology 88:141-148.

613 Kolbe JL, Ehrenberger JC, Moniz HA, Angilletta MJ. 2014. Physiological variation among 614 invasive populations of the Brown Anole (Anolis sagrei). Physiological and Biochemical 615 Zoology 87: 92-104.

616 Labunskay G, Meiri N. 2006. R-Ras3/(M-Ras) is involved in thermal adaptation in the critical 617 period of thermal control establishment. Journal of Neurobiology. 66:56-70.

618 Lanes O, Guddal PH, Gjellesvik DR, Willassen NP. 2000. Purification and characterization of a 619 cold-adapted uracil-DNA glycosylase from Atlantic cod (Gadus morhua). Comparative 620 Biochemistry and Physiology B: Biochemical Molecular Biology. 127:399-410.

621 Leppäluoto J, Pääkkönen T, Korhonen I, Hassi J. 2005. Pituitary and autonomic responses to cold 622 exposures in man. Acta Physiologica Scandinavia 184:255-264.ldstein, DL, West J, Rivera K, 623 Krane CM. 2007. Excretion and conservation of glycerol, and expression of aquaporins and 624 glyceroproteins, during cold acclimation in Cope's gray tree frog Hyla chrysochelis. 625 American Journal of Physiology: Regulatory and Integrative Comparative Physiology 292: 626 R544-R555. 
627 Maere S, Heymans K, Kuiper M. 2005. BiNGO: a Cytoscape plugin to assess overrepresentation 628 of Gene Ontology categories in biological networks. Bioinformatics 21:3448-3449.

629 McKechnie AE, Lovegrove BG. 2002. Avian facultative hypothermic responses: a review. $630 \quad$ Condor 104:705-724.

631 Michaelidis B, Loumbourdis NS, Kapaki E. 2002. Analysis of monoamines, adenosine and 632 GABA in tissues of the land snail Helix lucorum and lizard Agama stellio stellio during 633 hibernation. Journal of Experimental Biology. 205:1135-43.

634 Mishra A, Mohammad G, Thinlas T, Pasha MA. 2013. EGLN1 variants influence expression and $635 \mathrm{SaO} 2$ levels to associate with high-altitude pulmonary oedema and adaptation. Clinical $636 \quad$ Science London 124:479-89.

637 Moore LG, Shriver M, Bemis L, Hickler B, Wilson M, Brutsaert T, Parra E, Vargas E. 2004. 638 Maternal adaptation to high-altitude pregnancy: an experiment of nature-a review. Placenta. 63925 Suppl A:S60-71.

640 Muñoz MM, Stimola MA, Algar AC, Conover A, Rodriguez A, Landestoy MA, Bakken GS, 641 Losos JB. 2014. Evolutionary stasis and lability in thermal physiology in a group of tropical 642 lizards. Proceedings of the Royal Society, B 281:1778.

643 Narum, SR, Campbell NR, Meyer KA, Miller MR, Hardy RW. 2013. Thermal adaptation and 644 acclimation of ectotherms from differing aquatic climates. Molecular Ecology. 22:3090-3097.

645 Nasser NJ, Nevo E, Shafat I, Ilan N, Vlodavsky I, Avivi A. 2005. Adaptive evolution of 646 heparanase in hypoxia-tolerant Spalax: gene cloning and identification of a unique splice 647 variant. Proceedings of the National Academy of Sciences USA. 102:15161-15166.

648 Nesjum, LN, Kwon T-H, Jensen UB, Fumagalli O, Krane CM, Menon AG, King LS, Agre PA, 649 Nielsen S. 2002. Functional requirement of aquaporin-5 in plasma membranes of sweat 650 glands. Proceedings of the National. Academy of Sciences USA. 99:511-516. 
651 Newman, MEJ. 2005. A measure of betweenness centrality based on random walks. Social $652 \quad$ Networks 27:39-54.

653 Olufsen M, Smalås AO, Brandsdal BO. 2008. Electrostatic interactions play an essential role in 654 DNA repair and cold-adaptation of uracil DNA glycosylase. Journal of Molecular Modeling 655 14:201-13.

656 Ozgur A, Vu T, Erkan G, Radev DR. 2008. Identifying gene-disease associations using centrality 657 on a literature mined gene-interaction network. Bioinformatics 24:i277-i285.

658 Peng Y, Yang Z, Zhang H, Cui C, Qi X, Luo X, Tao X, Wu T, Ouzhuluobu, Basang, 659 Ciwangsangbu, Danzengduojie, Chen H, Shi H, Su B. 2011. Genetic variations in Tibetan 660 populations and high-altitude adaptation at the Himalayas. Molecular Biology \& Evolution. $661 \quad 2011: 1075-81$.

662 Petersen, AM, Gleeson TT, Scholnick DA. 2003.The effect of oxygen and adenosine on lizard 663 thermoregulation. Physiological and Biochemical Zoology 76:339-47.

664 Qiu Q, Zhang G, Ma T, Qian W, Wang J, Ye Z, Cao C, Hu Q, Kim J., Larkin DM, Auvil L, 665 Capitanu B, Ma J, Lewin HA, Qian X, Lang Y, Zhou R, Wang L, Liu J. 2012. The yak 666 genome and adaptation to life at high altitude. Nature Genetics 44:946-949.

667 Rajput C, Najib S, Norboo T, Afrin F, Qadar Pasha MA. 2006. Endothelin-1 gene variants and 668 levels associate with adaptation to hypobaric hypoxia in high-altitude natives. Biochemical 669 and Biophysical Research Communications. 341:1218-24.

670 Rebl A, Verleih M, Köbis JM, Kühn C, Wimmers K, Köllner B, Goldammer T. 2013. 671 Transcriptome profiling of gill tissue in regionally bred and globally farmed rainbow trout 672 strains reveals different strategies for coping with thermal stress. Marine Biotechnology $673 \quad 15: 445-460$

674 Rosenblum EB, Hoekstra HE, Nachman MW. 2004. Adaptive reptile color variation and the 675 evolution of the Mc1r gene. Evolution 58:1794-808. 
676 Saito S, Saito CT, Shingai R. 2008. Adaptive evolution of the uncoupling protein 1 gene

677 contributed to the acquisition of novel nonshivering thermogenesis in ancestral eutherian 678 mammals. Gene 408:37-44.

679 Savourey G, Garcia N, Caravel JP, Gharib C, Pouzeratte N, Martin S, Bittel J. 1998. Pre680 adaptation, adaptation and de-adaptation to high altitude in humans: hormonal and 681 biochemical changes at sea level. European Journal of Applied Physiology and Occupational $682 \quad$ Physiology. 77:37-43.

683 Sears MW, Angilletta MJ. 2011. Introduction to the symposium: Responses of organisms to 684 climate change: a synthetic approach to the role of thermal adaptation. Integrative and 685 Comparative Biology. 51:662-665.

686 Shannon P, Markiel A, Ozier O, Baliga NS, Wang JT, Ramage D, Amin N, Schwikowski B, 687 Ideker T. 2003. Cytoscape: a software environment for integrated models of biomolecular 688 interaction networks. Genome Research 13:2498-2504

689 Sharma P, Singh DP, Fatma N, Chylack LT Jr, Shinohara T. 2000. Activation of LEDGF gene by 690 thermal-and oxidative-stresses. Biochemical and Biophysical Research Communications. $691276: 1320-1324$.

692 Sookruksawonga S, Pongsomboona S, Tassanakajon, A. 2013. Genomic organization of the 693 cytosolic manganese superoxide dismutase gene from the Pacific white shrimp, Litopenaeus 694 vannamei, and its response to thermal stress. Fish \& Shellfish Immunology 35:1395-1405.

695 Storey KB. 2006. Reptile freeze tolerance: Metabolism and gene expression. Cryobiology 52:169616.

697 Sunday JM, Bates AE, Kearney MR, Colwell RK, Dulvy NK, Longino JT, Huey RB. 2014. 698 Thermal-safety margins and the necessity of thermoregulatory behavior across latitude and 699 elevation. Proceedings of the National Academy of Sciences USA 111:5610-5615. 
700 Suzuki M, Tanaka S. 2009. Molecular and cellular regulation of water homeostasis in anuran 701 amphibians by aquaporins. Comparative Biochemistry \& Physiology A: Molecular \& 702 Integrative Physiology 53:231-41.

703 Talbot DA, Duchamp C, Rey B, Hanuise N, Rouanet JL, Sibille B, Brand MD. 2004. Uncoupling 704 protein and ATP/ADP carrier increase mitochondrial proton conductance after cold adaptation 705 of king penguins. Journal of Physiology 558:123-35.

706 Tanaka A, Nakamura S, Mitsunaga F, Udono T, Suryobroto B. 2012. Human-specific SNP in 707 obesity genes, adrenergic receptor Beta2 (ADRB2), Beta3, and PPAR y2 (PPARG), during 708 primate evolution. PLoSone, DOI: 10.1371/journal.pone.0043461.

709 Tattersall G J, Cadena V, Skinner MC. 2006. Respiratory cooling and thermoregulatory coupling $710 \quad$ in reptiles. Respiratory Physiology \& Neurobiology 154:302-318.

711 Tavaria M, Gabriele T, Kola I, Anderson RL. 1996. A hitchhiker's guide to the human Hsp70 712 family. Cell Stress Chaperones.1:23-28.

713 Teulier L, Rouanet JL, Letexier D, Romestaing C, Belouze M, Rey B, Duchamp C, Roussel D. 714 2010. Cold-acclimation-induced non-shivering thermogenesis in birds is associated with 715 upregulation of avian UCP but not with innate uncoupling or altered ATP efficiency. Journal 716 of Experimental Biology. 213:2476-82.

717 Tewksbury JJ, Huey RB, Deutsch CA. 2008. Putting the heat on tropical animals. Science $718 \quad 320: 1296-1297$.

719 Tingaud-Sequeira A, Calusinska M, Finn RN, Chauvigne F, Lozano J, Cerda J. 2010. The 720 zebrafish genome encodes the largest vertebrate repertoire of functional aquaporins with dual 721 paralogy and substrate specificities similar to mammals. BMC Evolutionary Biology. 10:38.

722 Urban MC, Richardson JL, Friedenfels NA. 2013. Plasticity and genetic adaptation mediate 723 amphibian and reptile responses to climate change. Evolutionary Applications 7:88-103. 
724 Vedder O, Bouwhuis S, Sheldon BC. 2013. Quantitative assessment of the importance of

725 phenotypic plasticity in adaptation to climate change in wild bird populations. PLoS Biology

726 11(7): e1001605.

727 Vinagre C, Madeira D, Narciso L, Cabral H, Diniz M. 2012. Effect of temperature on oxidative 728 stress in fish: Lipid peroxidation and catalase activity in the muscle of juvenile seabass, 729 Dicentrarchus labrax. Ecological Indicators 23:274-279.

730 West-Eberhardt MJ. 2003. Developmental Plasticity and Evolution. Oxford University Press.

731 Xiang K, Ouzhuluobu, Peng Y, Yang Z, Zhang X, Cui C, Zhang H, Li M, Zhang Y, Bianba, 732 Gonggalanzi, Basang, Ciwangsangbu, Wu T, Chen H, Shi H, Qi X, Su. 2010. Identification of 733 a Tibetan-specific mutation in the hypoxic gene EGLN1 and its contribution to high-altitude 734 adaptation. Molecular Biology \& Evolution. 30:1889-1898.

735 Zimmerman SL, Frisbie J, Goldstein DL, West J, Rivera K, Krane CM. 2007. Excretion and 736 conservation of glycerol, and expression of aquaporins and glyceroporins, during cold 737 acclimation in Cope's gray tree frog Hyla chrysoscelis. American Journal of Physiology: 738 Regulatory, Integrative and Comparative Physiology. 292:R544-55. 


\section{Figure 1}

Flow chart of the process of identifying candidate functional pathways that are likely adaptive to changes in the thermal environment across vertebrates. Question marks denote hypothesis testing.

Yellow boxes denote research resources provided in this paper.
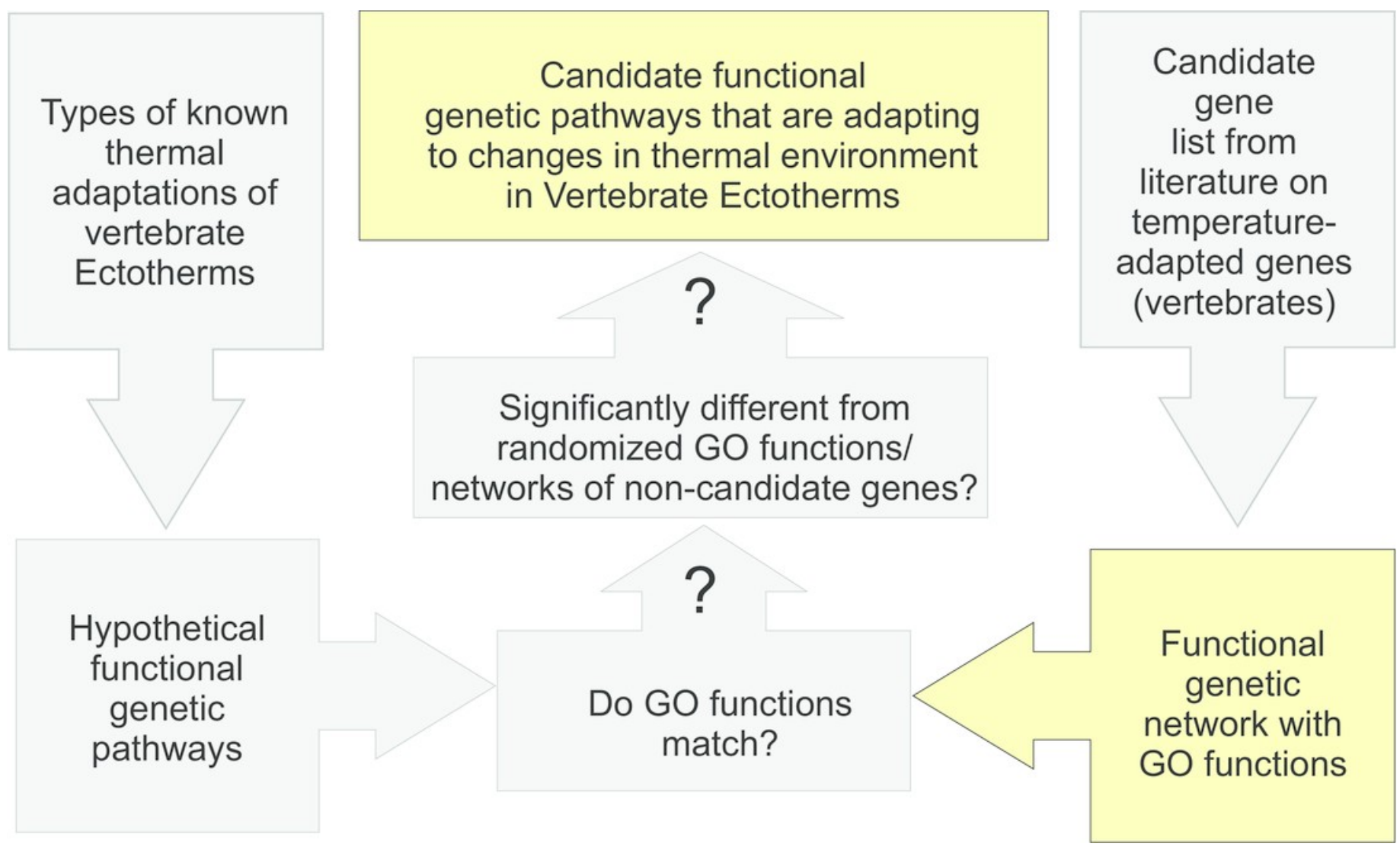


\section{Table 1 (on next page)}

Predicted and retrieved genetically overrepresented functions of candidate markers for thermal adaptation in a functional genetic network constructed for the chicken.

Error probabilities for genetic overrepresentation are derived from the test for Hypergeometric distribution, after Benjamini-Hochberg correction for multiple samples. 


\begin{tabular}{|c|c|}
\hline Predicted Functions & $\begin{array}{l}\text { Retrieved significantly overrepresented } \\
\text { Gene Ontologies }(p<0.05)\end{array}$ \\
\hline $\begin{array}{l}\text { Associated with the lipoprotein } \\
\text { metabolism }\end{array}$ & $\begin{array}{l}\text { LPL, CD36, CETP, MAPK1, MAPK14, } \\
\text { SOD1, STUB1, LEPR, UCP3 }\end{array}$ \\
\hline 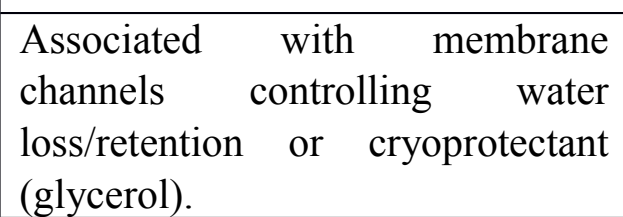 & LPL, CETP \\
\hline Associated with stress response & $\begin{array}{l}\text { MAPK1, UCP3, HSF1, MAPK14, HSP47, } \\
\text { UNG, HSPB2, SOD1, STUB1, HSPA8 }\end{array}$ \\
\hline $\begin{array}{l}\text { Associated with phenotypic or } \\
\text { phenological changes arising as a } \\
\text { consequence to thermal change, } \\
\text { e.g., pigmentation }\end{array}$ & Not overrepresented \\
\hline Associated with signal relay & $\begin{array}{l}\text { MAPK1, UCP3, HSF1, ADORA2B, ADRB2, } \\
\text { MAPK14, HSP47, UNG, HSPB2, MC4R, } \\
\text { SOD1, STUB1, HSP48, EGFR, CD } 36 \text {, } \\
\text { MRAS, ADORA1 }\end{array}$ \\
\hline $\begin{array}{l}\begin{array}{l}\text { Additional functions, not } \\
\text { predicted }\end{array} \\
\text { n }\end{array}$ & \\
\hline $\begin{array}{l}\text { Associated with oxidative stress } \\
\text { response }\end{array}$ & UCP3, SOD1 \\
\hline $\begin{array}{l}\text { Muscle contraction and relaxation, } \\
\text { muscle development }\end{array}$ & ADORA2B, SOD1, HSPB2 \\
\hline $\begin{array}{l}\text { Vasodilation, blood circulation, } \\
\text { blood pressure regulation }\end{array}$ & ADORA2B, SOD1, POMC \\
\hline
\end{tabular}




\section{Table 2 (on next page)}

Mann-Whitney $U$ test (with continuity correction) for difference in presence/absence of candidate functions retrieved from candidate gene network and randomized networks.

The candidate gene network recovered significantly more GO candidate functions than the random networks. 


\begin{tabular}{|l|l|l|l|l|}
\hline $\mathrm{U}$ & $\mathrm{Z}$ & $\mathrm{p}$-value & $\begin{array}{l}\text { Valid N } \\
\text { Randomized } \\
\text { neighbors }\end{array}$ & $\begin{array}{l}\text { Valid N } \\
\text { Candidate genes }\end{array}$ \\
\hline $\begin{array}{l}146764 . \\
5\end{array}$ & -8.285 & $1.187 * \mathrm{E}^{-16}$ & 2883 & 165 \\
\hline
\end{tabular}




\section{Figure 2}

Amniote phylogeny based on 3,994 one-to-one orthologous synonymous protein sites showing major features of amniote evolution.

Printed with permission from Alföldi et al., Nature 2011.

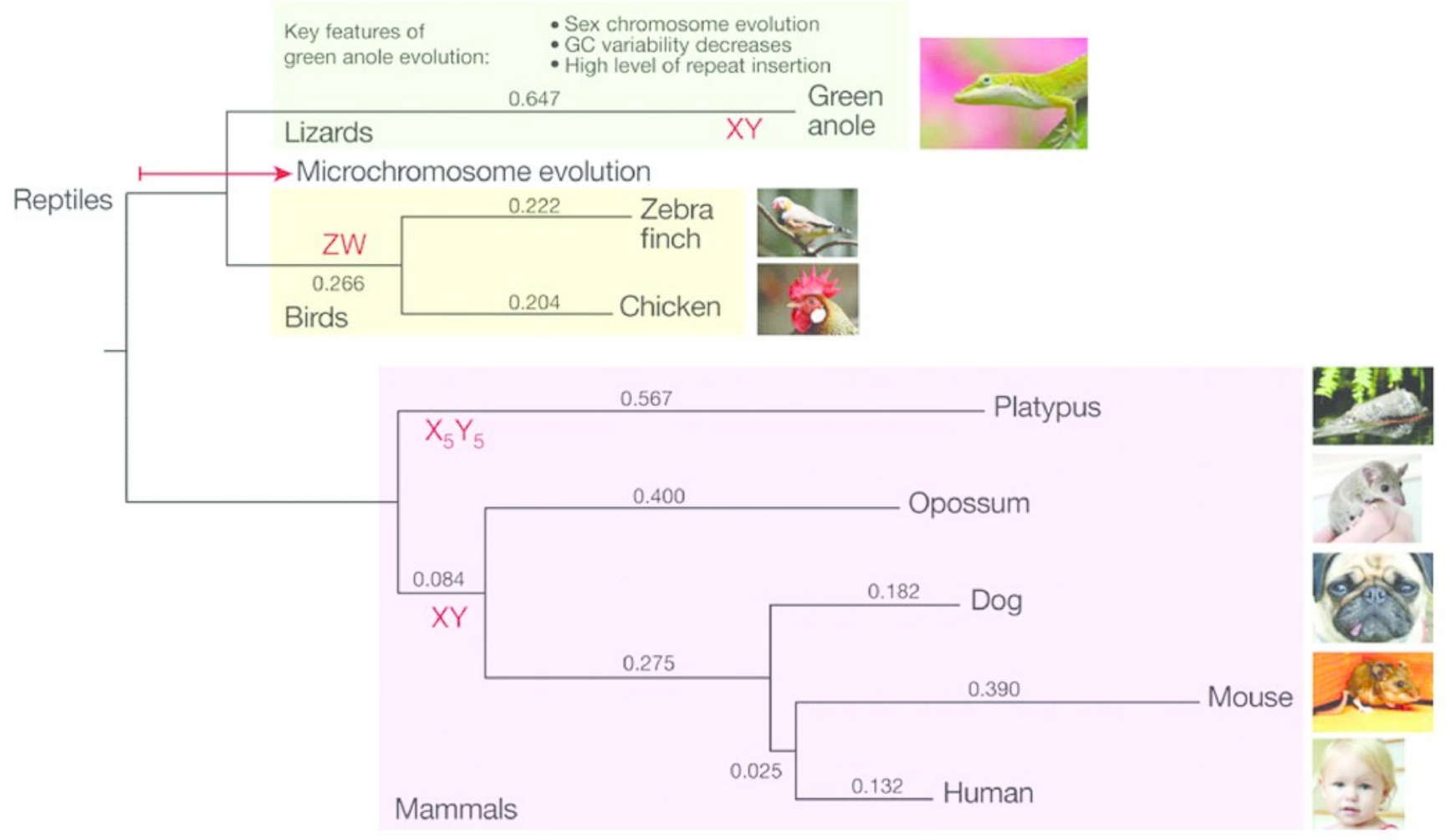




\section{Figure 3}

Large functional network of the chicken equivalents for a subset of candidate marker genes for thermal acclimation and adaptation

Candidate markers are indicated in green, links to other networks (depicted in Figure 3 and 4) in pink. Hypothetical connections manually inferred from human genes to connect parts of chicken networks (NPR) shown in hexagonal box. A detailed version of this figure can be accessed in Supplementary Figure 1

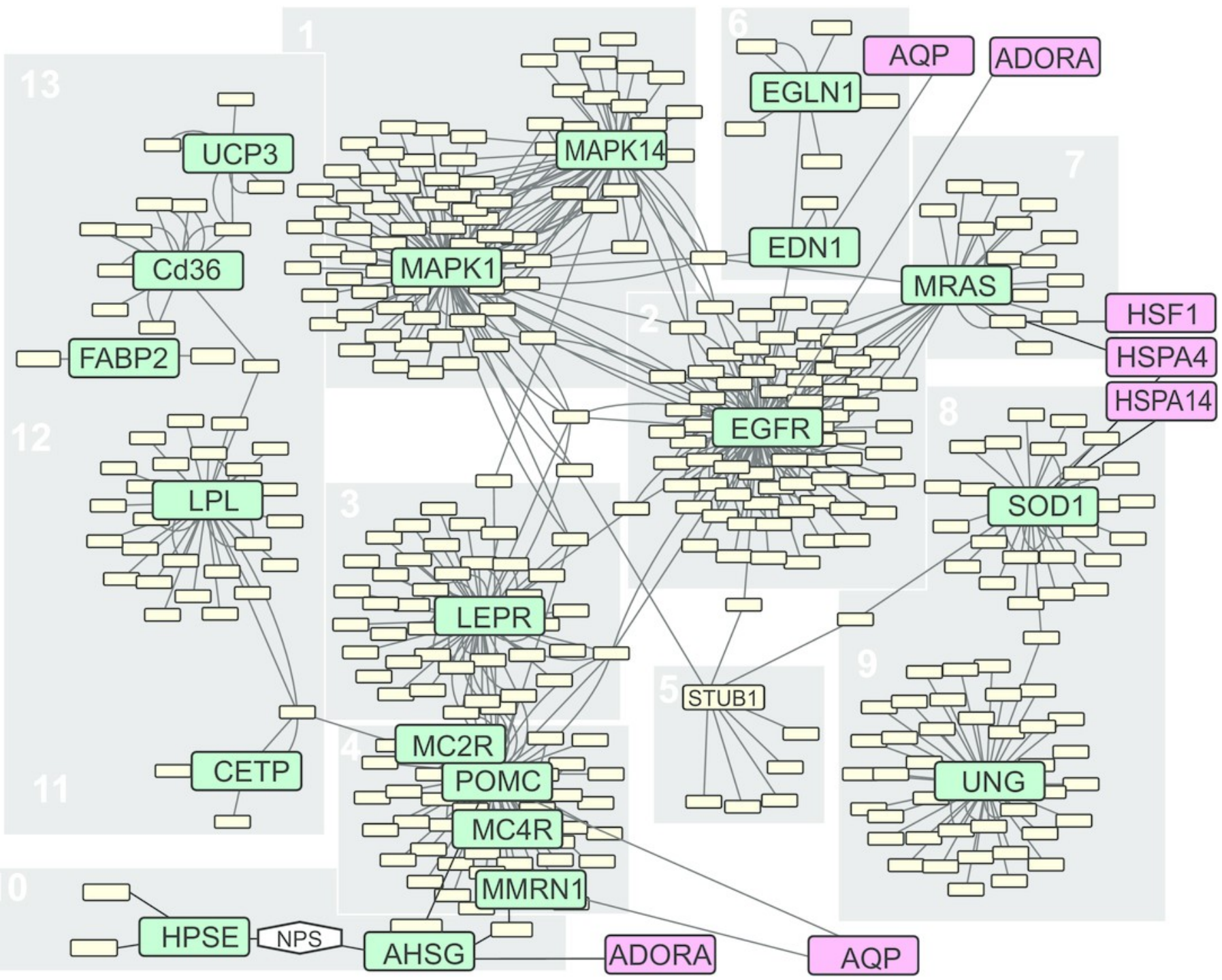




\section{Figure 4}

Aquaporin and Heat shock protein functional networks of the chicken equivalent for a subset of candidate marker genes for thermal acclimation and adaptation

Candidate markers are indicated in green. Hypothetical connections manually inferred from human genes to connect parts of chicken networks (NPPA, SUMO1) are shown in hexagonal boxes. Dashed lines - hypothetical functional association with the large network depicted in Figure 2

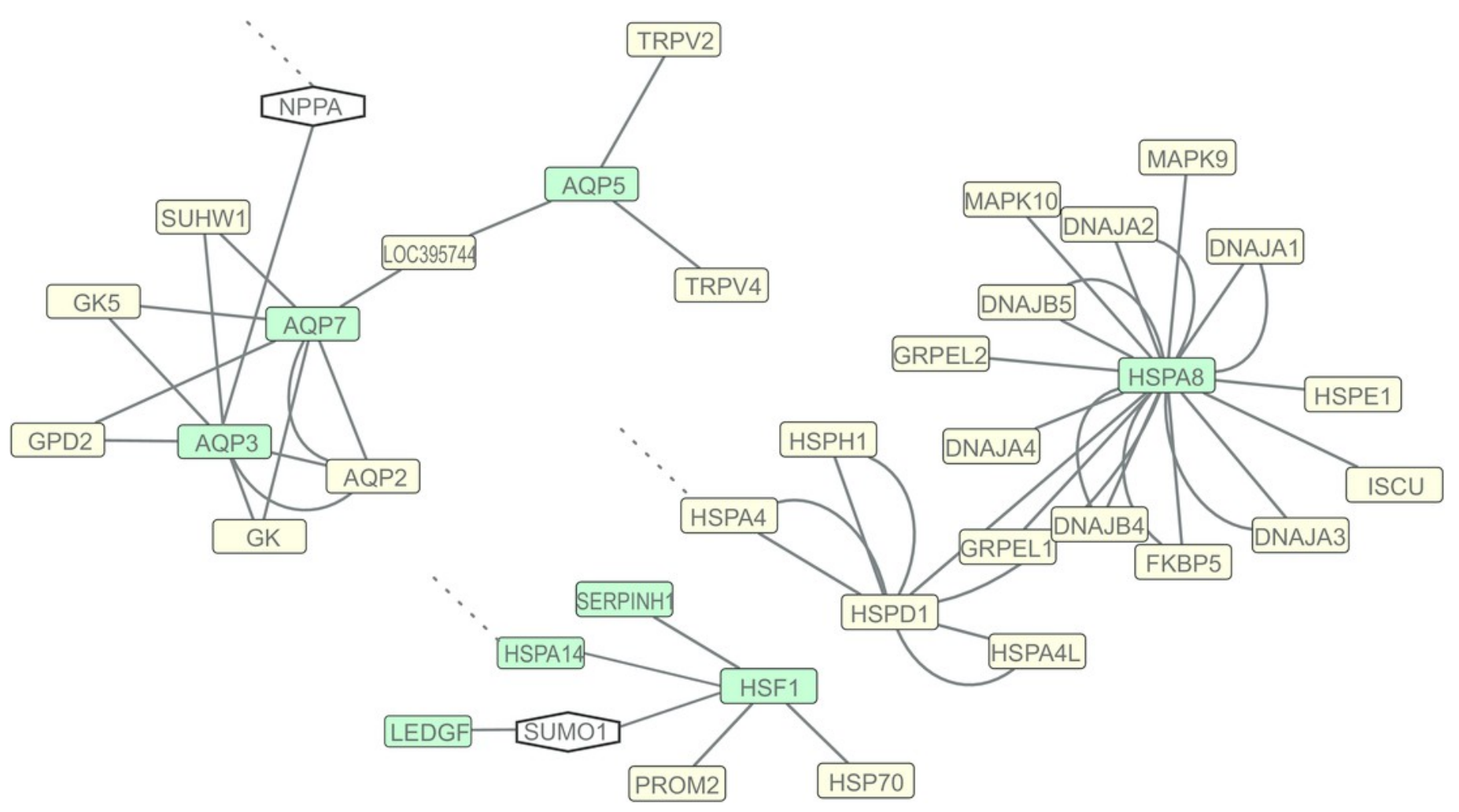




\section{Figure 5}

Figure 4

Functional Networks of the chicken equivalent for the ADORA Functional Network. Candidate markers in green. Dashed line - functional association with the large network depicted in Figure 2. 


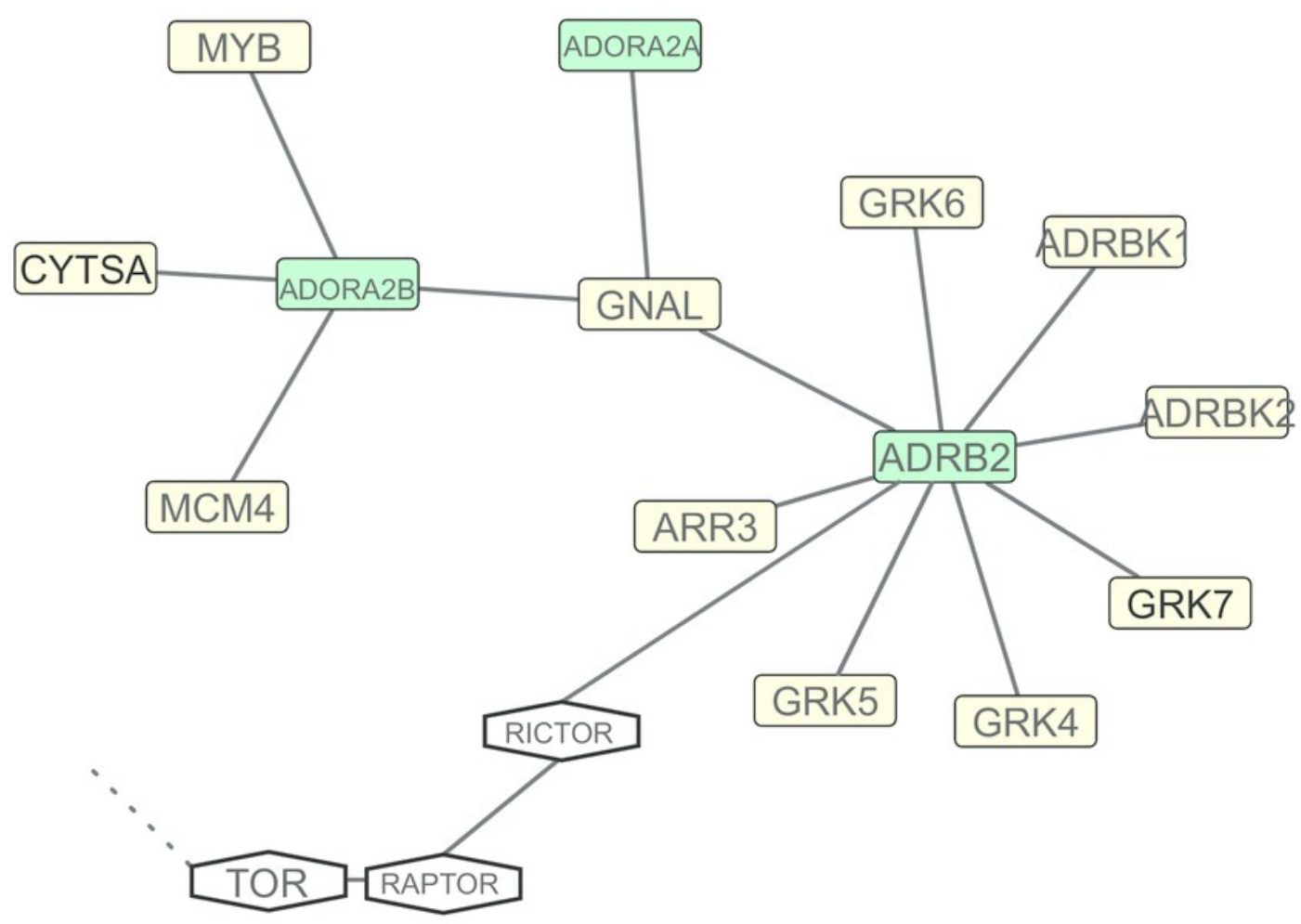




\section{Figure 6}

Comparison of a) clustering coefficients, b) network heterogeneity, c) network density and d) average closeness centrality of candidate and 50 randomized networks.

Candidate gene network neighbors (bar) are significantly less connected, nodes are equally heterogeneous, the network is significantly more dense (= functionally related), and has a significantly larger closeness centrality than the randomized neighbor networks (columns). 

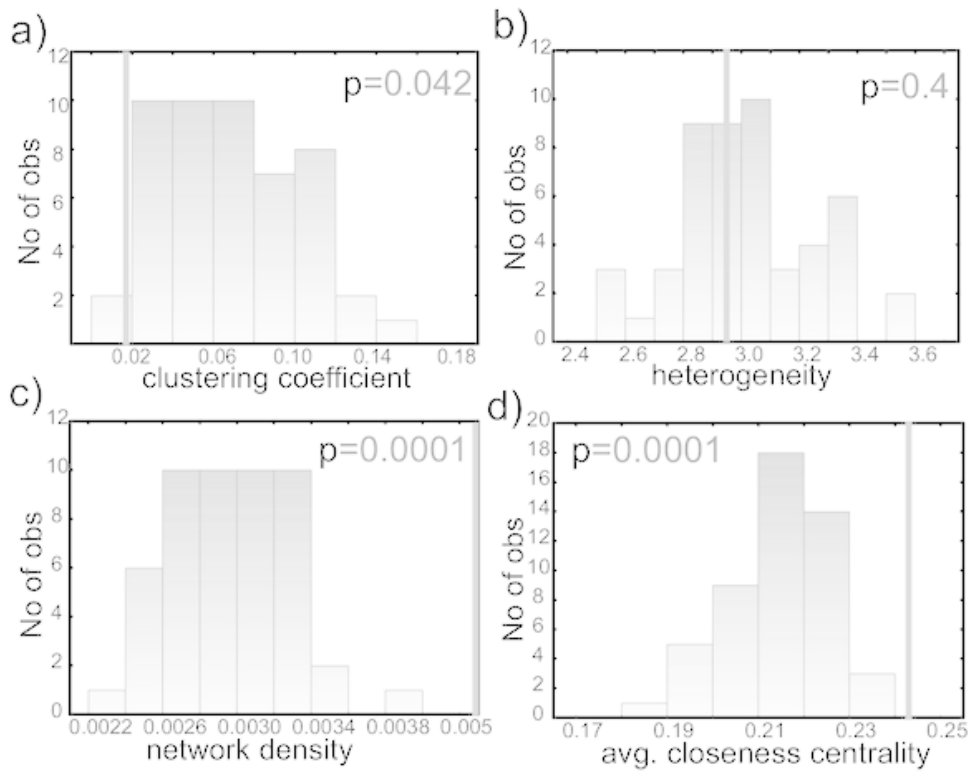